\title{
Presença da cultura italiana no município de Maravilha/SC: crenças e atitudes ${ }^{1}$
}

\author{
Presencia de la cultura italiana en el municipio de Maravilha/SC: \\ creencias y actitudes
}

\author{
The presence of the Italian culture in the town of Maravilha/SC: beliefs \\ and attitudes
}

\author{
Nadieli Mara Hullen Gerei ${ }^{2}$
}

\begin{abstract}
Resumo
A expressividade numérica de emigrantes italianos no Brasil é inegável, assim como os traços de sua língua e cultura na vida e cotidiano dos descendentes brasileiros. Segundo dados do IBGE (2000), estima-se que no período de maior emigração para o Brasil (1880-1950) tenham viajado mais de um milhão e meio de italianos, sendo mais de 26\% da região do Vêneto. Nos estados do Espírito Santo, Rio Grande do Sul e Santa Catarina, $65 \%$ da população é de origem italiana, sendo pelo menos a metade descendentes vênetos. Sendo a cidade de Maravilha/SC situada no Oeste Catarinense, portanto destino de muitos emigrantes, procuraremos pesquisar como essa cultura se manteve viva nesta cidade, como seus descendentes a consideram e em que medida existem políticas públicas de preservação dessa identidade. Amparada na Sociolinguística e na Sociologia da Linguagem, esta pesquisa se apresenta como um estudo inicial de pesquisa de doutorado que procurará, por meio de levantamento teórico, aplicação de questionário e realização de entrevistas, observar em qual geração (variação diacrônica ou diageracional), ambiente (variação diatópica - urbano x rural) e sexo (variação diassexual) as manifestações da cultura italiana são mais presentes e porquê isso acontece. Nesta etapa, apresentaremos resultados de sondagem inicial da pesquisa sobre observações gerais do município realizadas até o momento.
\end{abstract}

Palavras-Chave: Crenças e Atitudes; Cultura italiana; Emigração italiana.

\section{Resumen}

La expresividad numérica de emigrantes italianos en el Brasil es innegable, así como los rasgos de su lengua y cultura en la vida y cotidiano de los descendientes brasileños. Según datos del IBGE (2000), se estima que en el periodo de mayor emigración para el Brasil (1880-1950) tengan viajado más de un millón y medio de italianos, siendo más de $26 \%$ de la región del Véneto. En los estados de Espírito Santo, Rio Grande do Sul y Santa Catarina, $65 \%$ de la población es de origen italiana, la mitad corresponde a descendientes vénetos. Considerando la localización de la ciudad de Maravilha/SC, en el Oeste Catarinense, por lo tanto, destino de muchos inmigrantes, buscaremos investigar como esa cultura se ha mantenido viva en esta ciudad, como sus descendientes la consideran y en que medida existen políticas públicas de preservación de esa identidad. Apoyada en la Sociolingüística y en la Sociología del Lenguaje, esa investigación se caracteriza como un estudio inicial de la investigación del doctorado que buscará, por medio del levantamiento teórico, aplicación de cuestionario y realización de entrevistas observar en cual generación (variación diacrónica o diageracional), ambiente (variación diatópica - urbano x rural) y sexo (variación diassexual) las manifestaciones de la cultura italiana son más presentes y por qué eso ocurre. En esta etapa, presentaremos los resultados de sondeo inicial de investigaciones sobre observaciones generales del municipio realizadas hasta el momento.

\footnotetext{
${ }^{1}$ Artigo apresentado no Simpósio Temático ST 01 - A perspectiva intercultural em estudos sobre língua(s) de imigrantes e de fronteiras durante o II Seminário Latino-Americano de Estudos em Cultura - SEMLACult em Foz do Iguaçu/PR, Brasil, 2018.

2 Mestre em Letras; UNIOESTE - Universidade Estadual do Oeste do Paraná; Cascavel, Paraná, Brasil; nadielimara@ hotmail.com.
} 
Palabras claves: Creencias y Actitudes; Cultura italiana; Emigración italiana.

\begin{abstract}
The numerical expressiveness of Italian immigrants in Brazil is undeniable, as well as traits of its language and culture in the daily lives of the Brazilian descendants. According to data by IBGE (2000), it is estimated that during the time of great immigration (1880-1950) more than one million and a half Italians came to Brazil, being more than 26\% from the region of Veneto. In the States of Espírito Santo, Rio Grande do Sul and Santa Catarina, $65 \%$ of the population is of Italian origin, of which at least a half are Veneto descendants. The town of Maravilha/SC being situated in the West of Santa Catarina State, therefore the destiny of many immigrants, we will try to research how this culture is kept alive in this town, how its descendants regard it and in what extent there are public policies in order to preserve that identity. Based on the Sociolinguistics and the Sociology of Language, this study is presented as an initial research of doctorate degree, which will try, throughout a theoretical survey, questionnaire application and interviews, observe in what generation (diachronic or diagenerational variation), environment (diatopic variation - urban vs. rural) and gender (diassexual variation) the manifestation of the Italian culture is more present and why it is so. In this stage, we will show the results of the initial surveys of the research about general observations done in the town so far.
\end{abstract}

Keywords: Beliefs and Attitudes; Italian Culture; Italian Immigration.

\title{
1. A emigração italiana em dados
}

Segundo dados do IBGE (2000), estima-se que no período de maior emigração para o Brasil (1880-1950) tenham viajado para o Brasil mais de um milhão e meio de italianos, sendo mais de $26 \%$ deles da região do Vêneto. Nos estados do Espírito Santo, Rio Grande do Sul e Santa Catarina, 65\% da população é de origem italiana, sendo pelo menos a metade descendentes vênetos. Ainda segundo dados do IBGE (2000), prevê-se que um em cada seis brasileiros é de origem italiana e que desses $40 \%$ tem descendência vêneta. A Fundação Migrantes descreve São Paulo como a maior metrópole italiana do mundo, com aproximadamente 15 milhões de ítalo-descendentes.

A expressividade numérica de emigrantes italianos no Brasil é inegável, assim como os traços de sua língua e cultura nos traços de seus descendentes e dos brasileiros que convivem ou conviveram com esses.

Ao chegar, os emigrantes se surpreendiam com a situação que encontravam em solo estrangeiro: matas fechadas, varíola, elevada mortalidade infantil e a descoberta de que seu papel era, principalmente, substituir a mão-de-obra escrava recém abolida.

Os emigrantes italianos aportavam principalmente no Rio Grande do Sul e no Espírito Santo, mas depois se estenderam para Santa Catarina, Paraná, Mato Grosso, Mato Grosso do Sul, Rondônia, Acre e outros estados. Trabalhavam, em sua maioria, na agricultura e na criação de suínos e aves.

Vencidas as dificuldades iniciais de comunicação e enfrentamento da nova realidade, os emigrantes procuraram abrir espaço entre a mata fechada e construírem casas para os seus. A devoção religiosa e o espírito familiar os uniu mais do que nunca, o que, além da 
necessidade, despertava o desejo de trabalhar e produzir. Essas facetas de suas origens transmitiram para os filhos e netos, e se encontram arraigadas até hoje, no orgulho de "ser italiano", e que são demonstradas na culinária, na arquitetura e na tradição religiosa.

De acordo com Vedovelli (2011), a maioria dos primeiros emigrantes ainda não falava o italiano, à época recém instituído como língua oficial do país. Apenas 0,4\% era de "classe nobre", com acesso a bens culturais e portanto, falante do italiano. Nas próximas levas, principalmente da década de 50 em diante, era mais comum que viessem falantes ou pessoas que já haviam conheciam minimamente o italiano.

Obrigados a encontrar um meio de comunicação, brasileiros e italianos criaram essa nova língua, o talián, que, segundo Bertini Malgarini, pode ser considerado uma língua étnica, que é definida como "a língua materna de uma comunidade num país que fala outra língua ou outras línguas" (BERTINI MALGARINI, 1994, p. 893). Para Miazzo, o talián é "uma língua neolatina, uma espécie de neta do velho latim vulgar da civilização romana" (MIAZZO, 2011, p. 33). Essa nova língua não traz apenas novos aspectos semânticos e sintáticos, mas também tradição cultural e linguística, e nos mostra a riqueza da diversidade.

\section{Aportes metodológicos da pesquisa}

Nossa pesquisa se insere na Sociolinguística e na Sociologia da Linguagem, pois pretendemos observar a língua e a cultura de um povo inserido em uma sociedade pluricultural e multilinguística, além de observar qual a concepção destes descendentes em relação às próprias origens.

Nossa pesquisa se classifica também como Aplicada e Qualitativa-quantitativa, pois, para resolver os problemas que nos são apresentados, observaremos o contexto social e as ações que os permeiam, para então aplicar uma metodologia adequada à realidade específica. Para Moita Lopes, a Linguística Aplicada é uma ciência social, já que seu foco é em problemas de uso da linguagem enfrentados pelos participantes do discurso no contexto social (MOITA LOPES, 1996, p. 19-20).

\section{Crenças e atitudes linguísticas}

Nas palavras de Aguilera (2008), 
Um traço definidor da identidade do grupo (etnia, povo) é a variedade linguística assumida e, desse modo, qualquer atitude em relação aos grupos com determinada identidade pode, na realidade, ser uma reação às variedades usadas por esse grupo ou aos indivíduos usuários dessa variedade, uma vez que normas e marcas culturais dos falantes se transmitem ou se sedimentam por meio da língua, atualizada na fala de cada indivíduo (AGUILERA, 2008, p. 106).

Ao optar pelo uso ou não de determinada variante, o falante está fazendo escolhas que revelam também seus sentimentos e valores em relação à comunidade da qual faz parte. Mais do que uma escolha pelo léxico ou pela fonética de uma variante, o indivíduo se posiciona como um todo na sociedade, demonstrando como se sente em determinado meio, quais seus juízos de valor sobre a comunidade e, até mesmo, até que ponto se sente parte dela.

De acordo com Calvet (2013), uma das maneiras pelas quais se percebe a influência das atitudes linguísticas é no comportamento das mulheres. Ele cita pesquisas de Trudgill (1974), entre outros autores, nas quais se percebe sempre uma maior preocupação por parte das mulheres em falar bem e se adequar à norma padrão. A principal razão que as levam a isso seria a maior necessidade de serem aceitas e bem vistas pela sociedade e por ocuparem cargos junto ao comércio. Justamente por desejarem estar mais próximas ao nível mais adequado de língua, procuram adaptar-se a norma padrão ou, mesmo sem utilizá-la, creem que o fazem (CALVET, 2013).

Porém, sabemos que mesmo a norma padrão sofre influências e, por isso, é heterogênea. De acordo com Levi Mattoso, "variantes, portanto, aparecem nas diferentes comunidades da fala, podem ocorrer dentro de uma mesma comunidade e mesmo entre indivíduos" (LEVI-MATTOSO, 1991, p. 152).

Para Bagno (2013), se falar de isolamento humano é impossível, o mesmo vale ao tratarmos de isolamento linguístico. O tempo, as migrações, a globalização, "tudo isso nos obriga a reconhecer que se é impossível falar de raça pura, de cultura pura, de tradição pura, também é impossível sequer pensar no conceito de língua pura” (BAGNO, 2013, p. 321).

Ainda, segundo o autor,

O conceito de LÍNGUA é e só pode ser um conceito sociológico, antropológico e político, ou seja, um conceito inseparavelmente entrelaçado com as crenças, superstições, juízos de valor, preconceitos, representações sociais e ideologia que circulam numa sociedade (BAGNO, 2013, p. 323, grifos do autor).

Para exemplificar sua afirmação, o autor utiliza a língua italiana, ou italiano, afirmando que ela é, na verdade 
O 'dialeto' toscano que foi eleito, por razões políticas, ideológicas e culturais [...] o rótulo de LÍNGUA ficou reservado para o toscano, enquanto todas as demais línguas foram rotuladas de 'dialeto', isto é, tradicionalmente um modo de falar menos nobre, menos culto, menos politicamente importante (BAGNO, 2013, p. 323, grifos do autor).

Esta afirmação vai ao encontro da fala cuja autoria se atribui a Weinreich, de que "uma língua é um dialeto com exército e marinha", pois o que torna um dialeto língua são questões políticas, e não linguísticas.

\section{Presença da cultura italiana em Maravilha/SC}

No início do século XX, 90\% do território a Oeste de Santa Catarina era formado por florestas. Em 1925, formou-se a Companhia Territorial Sul Brasil, cuja principal função era a de promover a ocupação de terras ociosas a Oeste do estado. À época, havia mais de nove mil lotes coloniais à venda. Além dos trabalhadores e empreiteiros da Companhia, as serrarias Sbaraini e Benvegnu também atraíram pessoas para a futura cidade.

Com a chegada de, principalmente, descendentes de alemães e italianos, a até então vila iniciou-se na agricultura, no comércio e nas madeireiras. $O$ lugarejo se tornou oficialmente município dia 27 de julho de 1958, por meio da Lei Estadual n. 348, de 21 de junho de 1958.

Maravilha é um município brasileiro situado no Oeste do estado de Santa Catarina. É a $45^{\mathrm{a}}$ maior cidade do estado de Santa Catarina. Com uma população de 22.104 habitantes (segundo dados do IBGE 2010), é localizado a $71 \mathrm{~km}$ de Chapecó e a $626 \mathrm{~km}$ de Florianópolis, capital do estado. O município é cortado pelo entroncamento de duas BRs (282 e 158).

É um município relativamente pequeno, com uma área de $169,45 \mathrm{~km}^{2}$. Os municípios limítrofes são Cunha Porã, Modelo, Tigrinhos, São Miguel da Boa Vista, Flor do Sertão, Iraceminha e Bom Jesus do Oeste.

Maravilha é um município brasileiro situado no Oeste do estado de Santa Catarina, que carrega orgulhoso o título de "Cidade das Crianças". É a $45^{a}$ maior cidade do estado de Santa Catarina. Com uma população de 22.104 habitantes (segundo dados do IBGE 2010), é localizado a $71 \mathrm{~km}$ de Chapecó e a 626 km de Florianópolis, capital do estado. O município é cortado pelo entroncamento de duas BRs (BR 282 e BR 158).

É um município relativamente pequeno, com uma área de 169,45 km². Os municípios limítrofes são Cunha Porã, Modelo, Tigrinhos, São Miguel da Boa Vista, Flor do Sertão, Iraceminha e Bom Jesus do Oeste. 


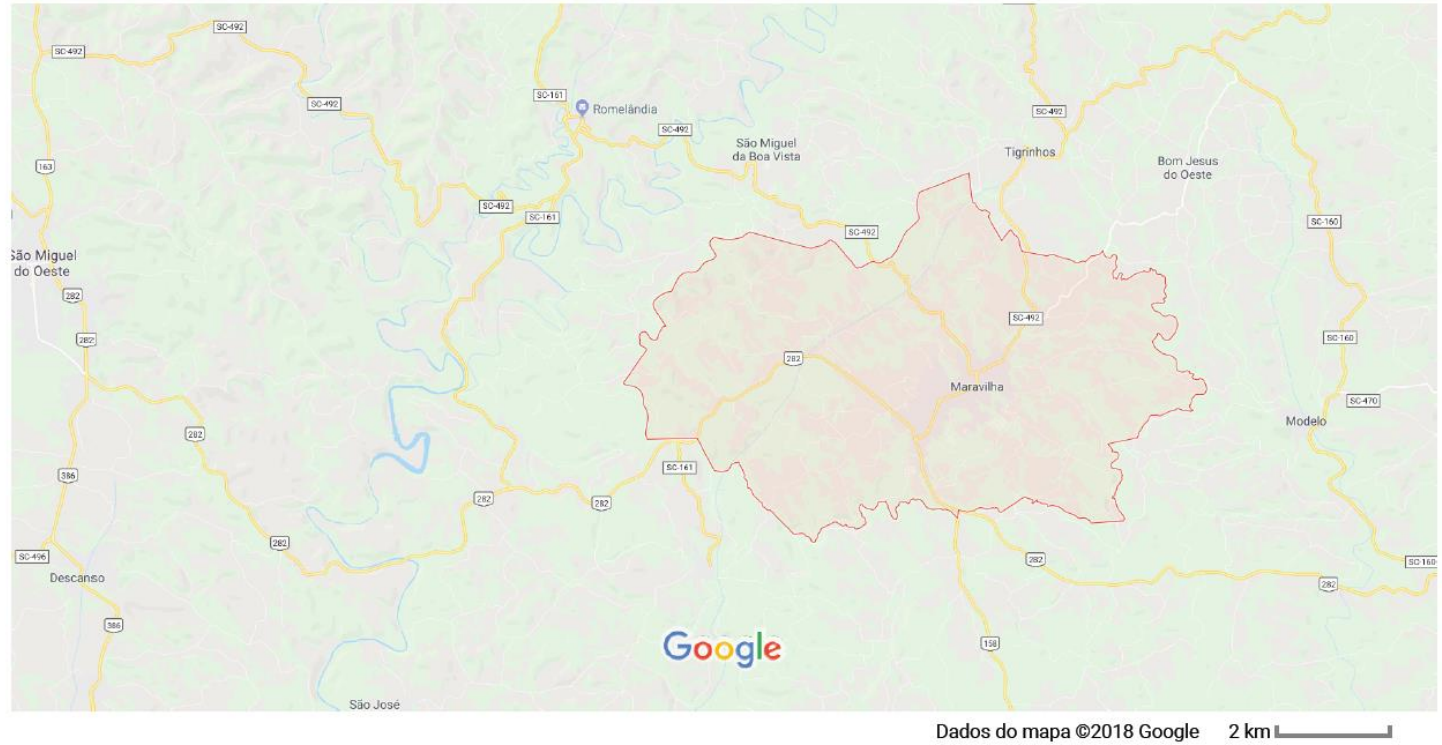

Figura 01: Mapa da área da cidade de Maravilha/SC. Fonte: adaptado de https://www.google.com.br/maps/place/Maravilha+-+SC/@-26.7555137,-

53.2673273,12z/data=!3m1!4b1!4m5!3m4!1s0x94fae5a81e8ad57b:0xbae6998a30795e4d!8m2!3d-26.755959!4d-

53.1965079

Sendo a cidade de Maravilha situada no Oeste Catarinense, portanto destino de muitos emigrantes, procuraremos perceber como essa cultura se manteve viva, como seus descendentes a consideram e em que medida existem políticas públicas de preservação dessa identidade.

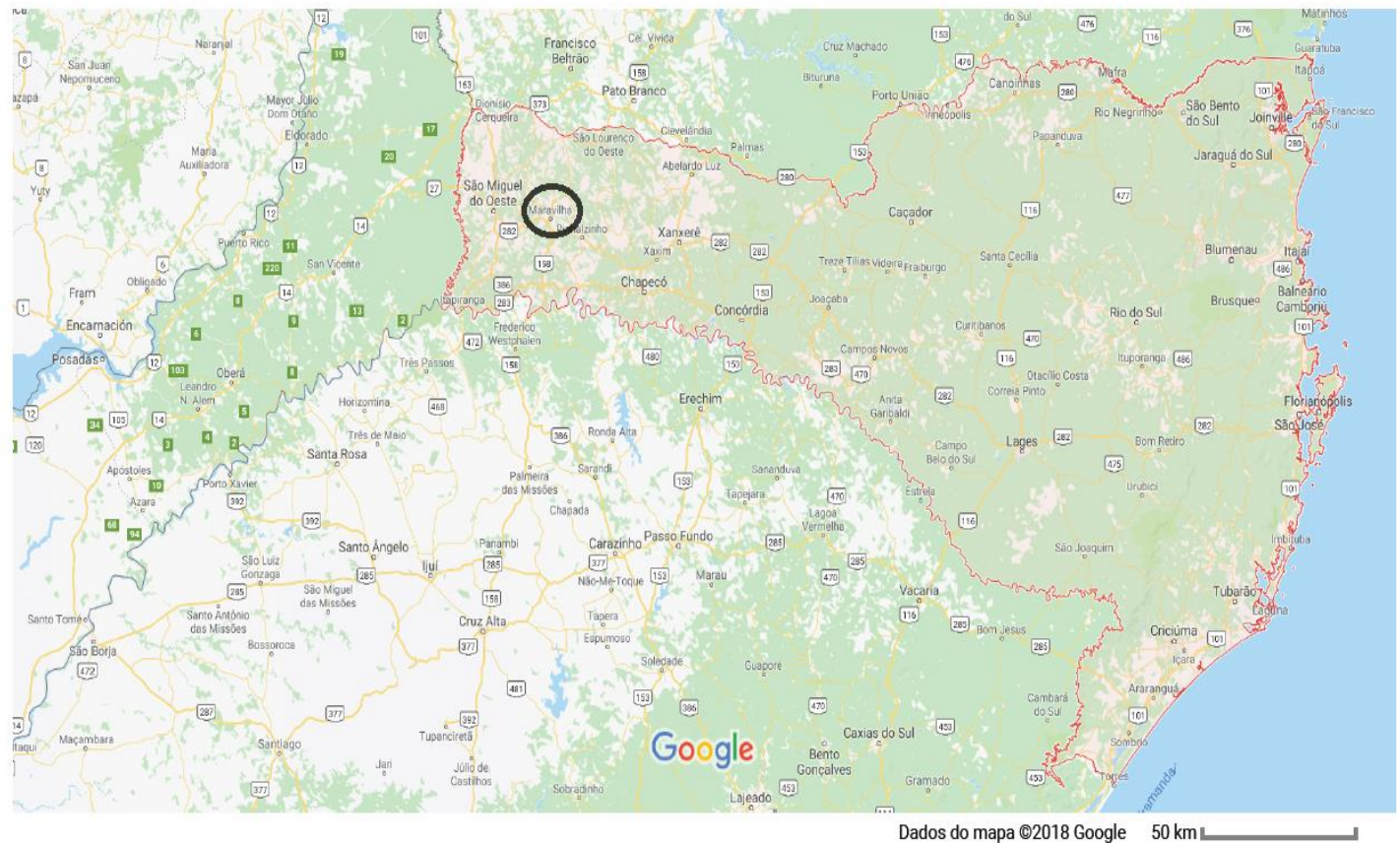

Figura 02: Mapa do estado de Santa Catarina com destaque para a cidade de Maravilha. Fonte: adaptado de https://www.google.com.br/maps/place/Santa+Catarina/@ -27.6491894,-

52.2535658,8z/data=!4m5!3m4!1s0x94d94d25c052fff9:0x2b277580ed7fab2b!8m2!3d-27.2423392!4d-50.2 
Em sondagens iniciais, observamos que há 22 anos é realizado o programa Hora Italiana, transmitido ao vivo todos os sábados das 14h30min às 16h00min na Rádio Difusora de Maravilha.

Neste programa, são debatidos temas gerais relativos a cultura italiana, culinária (receitas típicas), músicas e entrevistas com descendentes. O programa é realizado em talian, e ouvido e divulgado em toda a região.

O município também conta com a presença da ACIMA - Associação Cultural Italiana de Maravilha - SC. Fundada em 25 de Julho de 1992, possui sede própria situada na Avenida Araucária, n. 915 no centro de Maravilha. A ACIMA tem seu Grupo de Cantos que realiza seus ensaios todas as quintas-feiras das $19 \mathrm{~h} 00 \mathrm{~min}$ às $20 \mathrm{~h} 30 \mathrm{~min}$ em sua sede e participa de eventos e festas italianas em toda a região. Realiza duas festas italianas durante o ano nos meses de maio e setembro, respectivamente, quando recebe Grupos Italianos de toda a região, que apresentam três canções, necessariamente em talian. Participa também de missas na Igreja Matriz São João Operário, sempre no quarto sábado de cada mês às 19h00min.

Apesar de reconhecermos o estágio inicial da pesquisa, consideramos, até o momento, que a manifestação cultural italiana possui uma expressividade pequena no município, observando-se o número de descendentes na cidade.

Nas escolas, nota-se a realização de danças e celebração de algumas datas comemorativas, mas não há preocupação com o resgate histórico ou o significado de tais comemorações.

Não há políticas públicas claras ou conhecidas de tentativa de manutenção da língua e da cultura por parte administrativa/governamental do município, pois para a realização de suas atividades a comunidade utiliza-se de recursos próprios.

Percebe-se também uma aglutinação dos movimentos e das tradições nas gerações mais velhas, o que sugere que seus filhos e netos não tem interesse ou conhecimento na manutenção de hábitos de seus descendentes.

Em visita ao Museu Municipal de Maravilha/SC, encontramos vários objetos típicos trazidos por italianos e doados ao museu por descendentes: 
RELACult - Revista Latino-Americana de Estudos em Cultura e Sociedade

Revista Latinoamericana de Estudios en Cultura y Sociedad | Latin American Journal of Studies in Culture and Society V. 05, ed. especial, mai., 2019, artigo no 1451 | claec.org/relacult | e-ISSN: 2525-7870

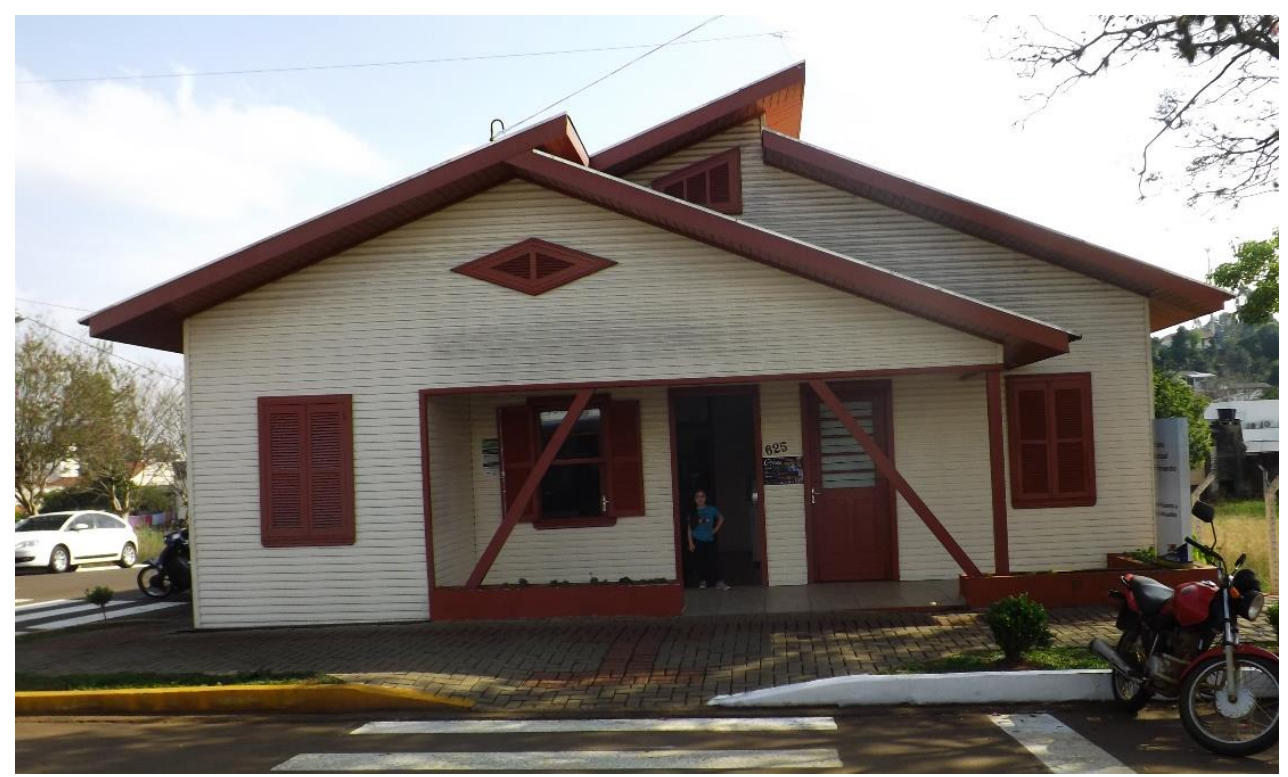

Figura 03 - Museu Municipal de Maravilha-Santa Catarina. Fonte: da pesquisadora.

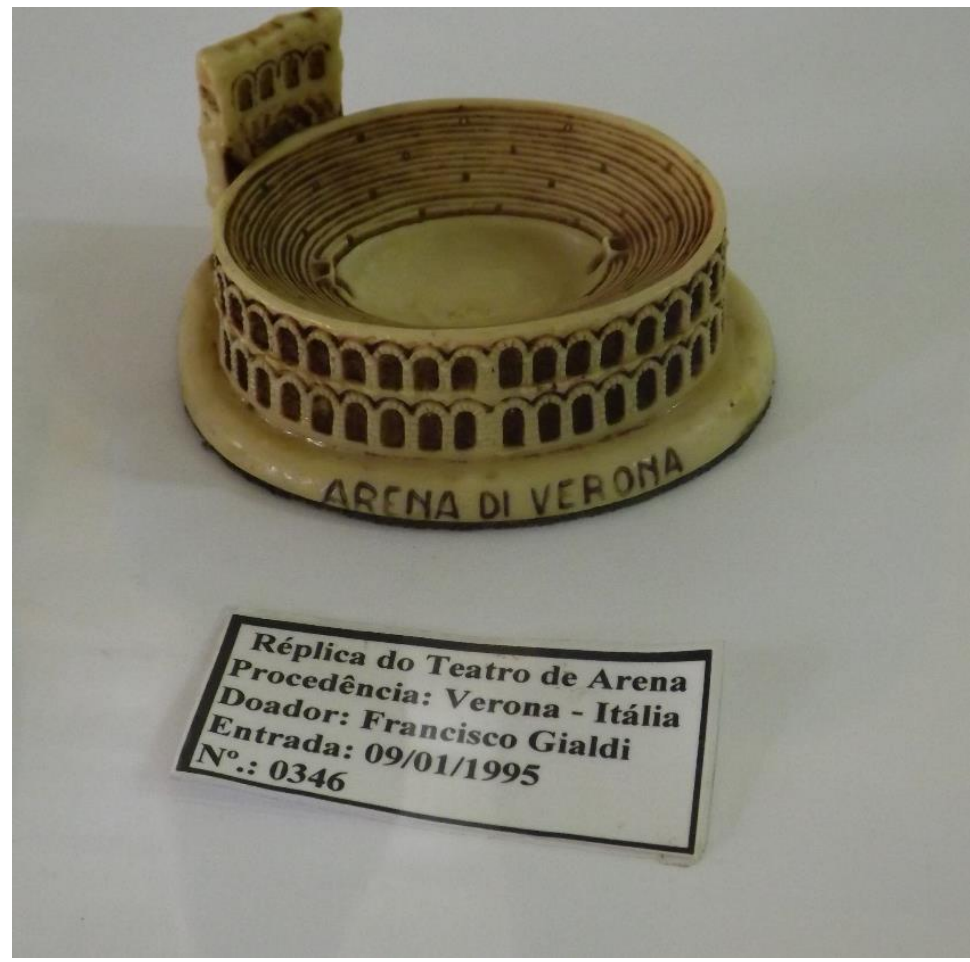

Figura 04 - Réplica do Teatro de Arena di Verona. Fonte: da pesquisadora. 
RELACult - Revista Latino-Americana de Estudos em Cultura e Sociedade

Revista Latinoamericana de Estudios en Cultura y Sociedad | Latin American Journal of Studies in Culture and Society V. 05, ed. especial, mai., 2019, artigo no 1451 | claec.org/relacult | e-ISSN: 2525-7870

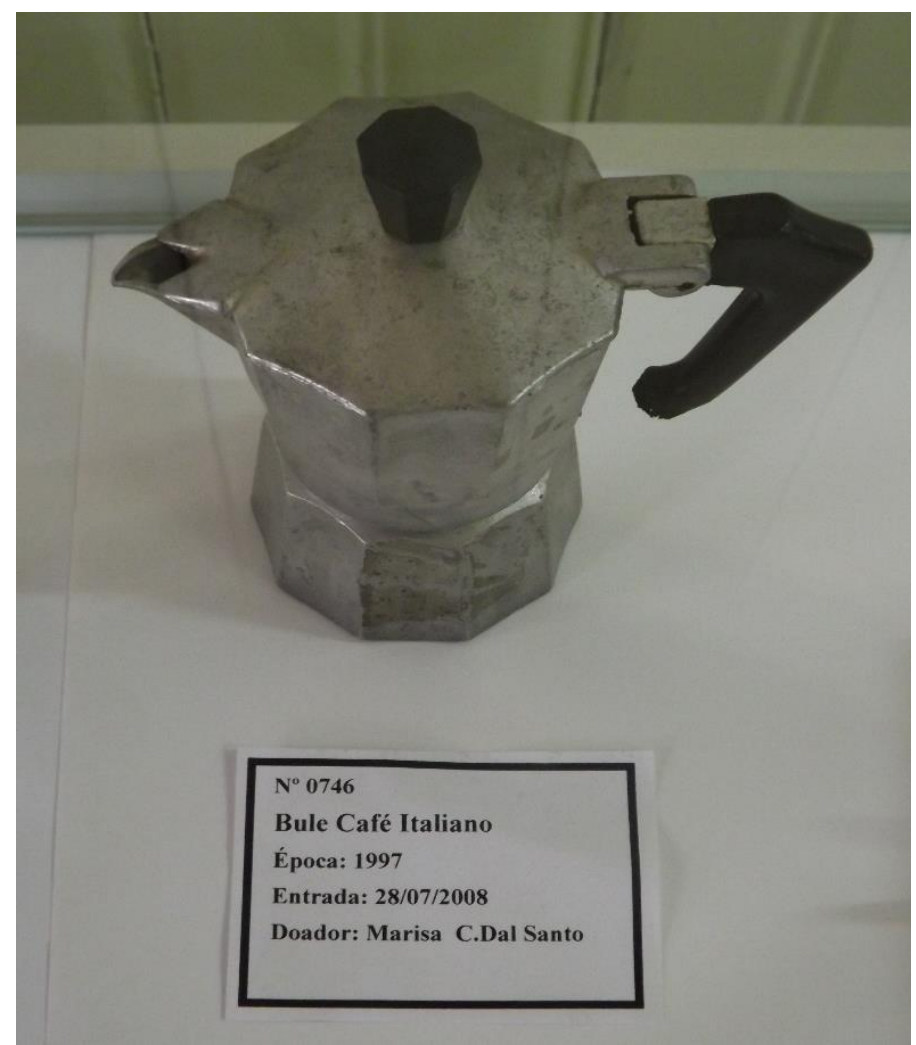

Figura 05 - Bule de café italiano. Tradicionalmente conhecido como "Mocca". Fonte: da pesquisadora.

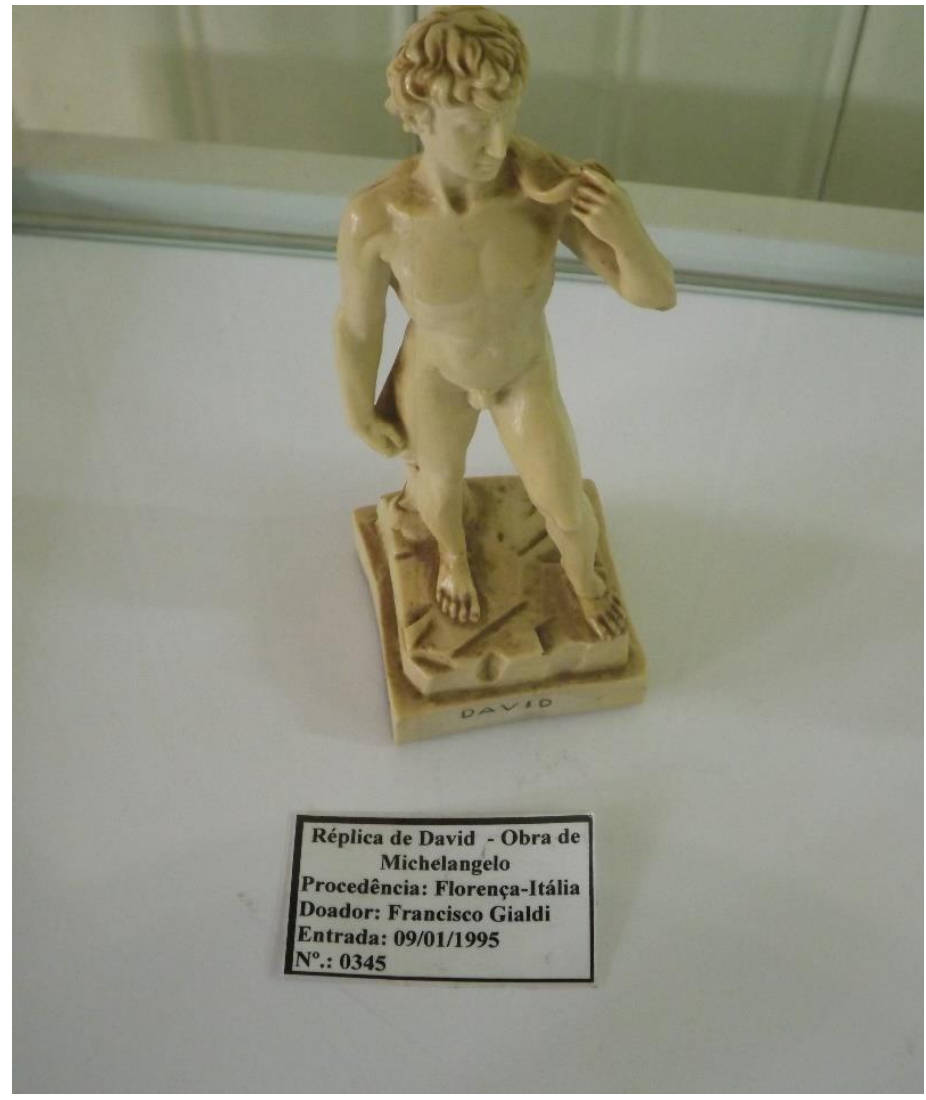

Figura 06 - Réplica da Estátua de David, obra de Michelangelo. Fonte: da pesquisadora. 
No dia 27 de julho a cidade de Maravilha comemora seu aniversário, em 2018 completou 60 anos. A ACIMA participa também do desfile, usando os trajes típicos italianos utilizados durante as festas e manifestações culturais:

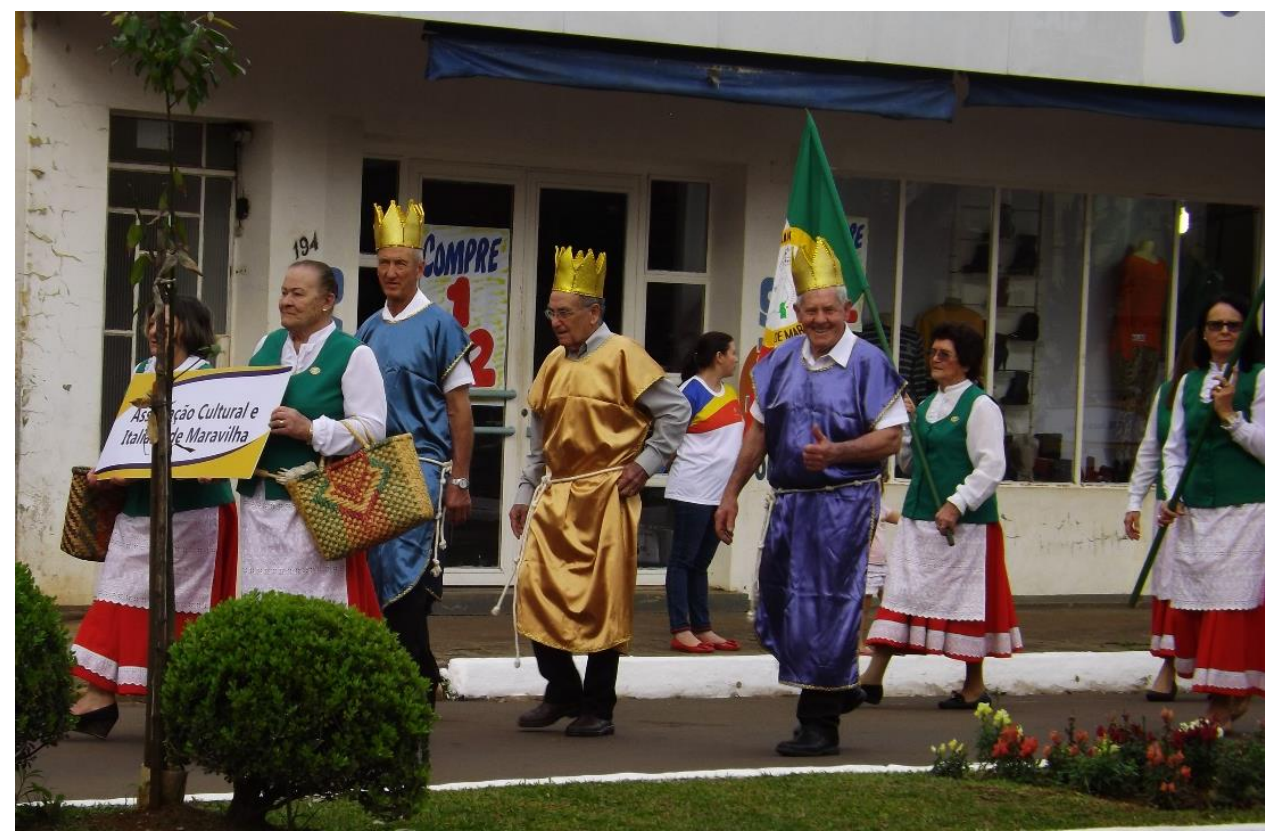

Figura 07 - ACIMA participando do desfile do $60^{\circ}$ aniversário de Maravilha em 27 jul. 2018. Fonte: da pesquisadora.

\section{5. À guisa de conclusão: o conceito de identidade}

Percebemos, por meio dos resultados obtidos, que, além de se adequar a um novo solo e território, houve também, nos imigrantes, uma transformação na própria identidade, provocada pela adaptação a uma nova língua e a consequente criação de uma nova cultura. Houve a formação de um novo grupo, de imigrantes europeus e asiáticos, em contato com exescravos e indígenas, e com isso novos costumes, tradições e ideologias, que se traduzem na própria identidade pessoal e coletiva, surgiram e se transformaram, assim como ocorre com todos os indivíduos sociais continuamente.

No contexto da emigração italiana, que se deu concomitante e posterior à unificação do país, muitos não se sentiam italianos, mas sim vênetos, lombardos, toscanos. Face ao cenário de solidão e de estrangeirismo, no entanto, tornavam-se todos italianos, mudando a maneira como viam a si mesmos.

O próprio conceito de identidade não pode mais ser visto como algo fixo e alheio ao contexto social do indivíduo. Rajagopalan (1998) assinala: 
A identidade de um indivíduo se constrói na língua e através dela. Isso significa que o indivíduo não tem uma identidade fixa anterior ou fora da língua. Além disso, a construção da identidade de um indivíduo na língua e através dela depende do fato de a própria língua em si ser uma atividade em evolução e vice-versa. Em outras palavras, as identidades da língua e do indivíduo tem implicações mútuas. Isso por sua vez significa que as identidades estão sempre num estado de fluxo (RAJAGOPALAN, 1998, p. 41-42).

Damke (1998) acrescenta que língua e identidade são conceitos que se completam; não se pode falar em língua sem relacioná-la à identidade do próprio falante e da formação da identidade do indivíduo sem observar aspectos culturais, que vão para além da língua.

De acordo com Krug (2004), a língua é um fator determinante para a formação da identidade e da etnicidade de uma comunidade. Para o autor, "quanto maior o papel da língua como marca de identidade, tanto maior as possibilidades de uso e manutenção da língua minoritária" (KRUG, 2004, p. 12). Isso porque ao permanecer se comunicando na língua da pátria, traz consigo também crenças e atitudes do país de origem.

Ao estudar a comunidade de Imigrantes (Rio Grande do Sul), o autor percebe que muitas vezes o uso da língua portuguesa pelos emigrantes coincide com a troca do meio rural pelo trabalho nas indústrias ou pequenas empresas. Essa realidade se justifica, não somente nessa comunidade de emigrantes, mas também em outras em que se deu o êxodo rural pelas dificuldades encontradas no campo e pelas melhores perspectivas, até mesmo de escolarização, ofertadas pelo meio urbano.

Conforme considerações de Krug (2004), há fatores que favorecem o bilinguismo, em convivência "pacífica" com a língua portuguesa, e outros que o desfavorecem. A escola, ao culpar o bilinguismo pelo fracasso escolar, pode representar uma das motivações negativas para sua manutenção (ALTENHOFEN, 2002).

Como representações de manutenção, além da língua, temos as danças e festas típicas, a arquitetura, as igrejas (em sua maioria católicas para os italianos e luterano-protestantes para os alemães), o nome de estabelecimentos comerciais, os sobrenomes, entre outros. É possível, então, não falar a língua, uma vez que sua etnia está representada por outros símbolos (KRUG, 2004). Conforme Arendt e Pavani (2006),

Nas comunidades italianas, o padre era o mais poderoso elemento da ordem e da moralidade, tendo um domínio tão grande sobre a vida dos colonos, que esses dependiam do seu juízo até para tomadas de decisão econômicas e comerciais [..] o poder da Igreja sobre a 
comunidade de imigrantes se ampara na estrutura familiar tradicional e em rígidos conceitos de moral (ARENDT; PAVANI, 2006, p. 236).

Assim como os demais elementos de representação simbólica, a igreja também é um elemento influenciador na construção da identidade de um indivíduo ou de uma comunidade. Para os governantes na época, era importante a presença dos religiosos, visto que "o sermão dos padres ajuda os colonos a suportarem, com paciência e fé, as agruras do trabalho na lavoura, criando neles o sentimento de conformidade e submissão às autoridades" (ARENDT; PAVANI, 2006, p. 237). Para facilitar a presença desses, "Em vista do grande poder que a religião exercia sobre a conduta social dos colonos, as próprias autoridades propunham a construção de igrejas" (ARENDT; PAVANI, 2006, p. 237).

Isso acontece, segundo os autores, porque "a religião, com seu universo simbólico, cumpre o papel de congregar a maioria dos indivíduos em torno de certos rituais e de produzir sempre novos sentidos para sua identidade (ARENDT; PAVANI, 2006, p. 237).

Observando os elementos citados como partes da construção de uma identidade e, baseando-nos em Krug (2004), podemos afirmar que a identidade é dinâmica, heterogênea, multifacetada, múltipla (KRUG, 2004).

\section{Referências}

AGUILERA, V. A. Crenças e atitudes lingüísticas: o que dizem os falantes das capitais brasileiras. Estudos Lingüísticos, São Paulo, v. 37, n. 02, p. 105-112, maio-ago. 2008.

ALTENHOFEN, Cléo Vilson. O conceito de língua materna e suas implicações para o bilingüismo (em alemão e português). In: Martius-Staden-Jahrbuch, São Paulo, n. 49, p. 141161, 2002.

ARENDT, J.C.; PAVANI, C.F. América: a anti-utopia da imigração italiana. UCS, Caxias do Sul, v. 5, n. 9, p. 219-241, jan./jun. 2006.

BAGNO, M. Do galego ao brasileiro, passando pelo português: crioulização e ideologias linguísticas. In: LOPES, L. P. da. O Português no Século XXI: cenário geopolítico e sociolinguístico. São Paulo: Parábola, 2013. p. 319-338.

BERTINI MALGARINI, P. L'italiano fuori l'Italia. In.: SERIANNI, L.; TRIFONI, P. Storia della lingua italiana. Einaudi: Torino, p. 883-922.

CALVET, L. J. Sociolinguística: uma introdução crítica. 2. ed. São Paulo: Parábola, 2013.

Dados estatísticos 2010.2 Disponível em: https://ww2.ibge.gov.br/home/estatistica/populacao/censo2010/tabelas_pdf/total_populacao_s anta_catarina.pdf. Acesso em 19 julho 2018. 
DAMKE, Ciro. Variação linguística e a construção do sujeito. In.: JORNADA DE ESTUDOS LINGUÍSTICOS E LITERÁRIOS, 1., 1998, Marechal Cândido Rondon/PR. Anais... Marechal Cândido Rondon/PR, 1998, sem p.

KRUG, M. J. Identidade e comportamento linguístico na percepção da comunidade plurilíngue alemão-italiano-português de Imigrante-RS. 2004. 131 f. Dissertação (Mestrado em Letras). Universidade Federal do Rio Grande do Sul, Porto Alegre.

LEVI-MATTOSO, M. Relação entre Psicolingüística (ou: por uma Psicossociolingüística). Ilha do Desterro, Florianópolis, v. 25-26, p. 151-166. 1991.

Mapa do Estado de Santa Catarina. Disponível em: https://www.google.com.br/maps/place/Santa+Catarina/@-27.6491894,-

$52.2041273,8 \mathrm{z} / \mathrm{data}=! 3 \mathrm{~m} 1$ ! $4 \mathrm{~b} 1$ !4m5!3m4!1s0x94d94d25c052fff9:0x2b277580ed7fab2b!8m2! 3d-27.2423392!4d-50.2188556. Acesso em: 19 julho 2018.

Mapa do Estado de Maravilha-SC. Disponível em: https://www.google.com.br/maps/place/Maravilha+-+SC/@-26.7555137,-$53.2673273,12 \mathrm{z} /$ data $=! 3 \mathrm{~m} 1$ !4b1!4m5!3m4!1s0x94fae5a81e8ad57b:0xbae6998a30795e4d!8m 2!3d-26.755959!4d-53.1965079. Acesso em: 19 julho 2018.

MIAZZO, G. Descobrindo o talian: viagem só de ida para a Mérica. Muçum/RS: Muçum, 2011.

MOITA LOPES, Luiz Paulo da. Oficina de lingüística aplicada. Campinas, SP: Mercado das Letras, 1996.

Portal Brasil Talian. Disponível em: http://www.brasiltalian.com/2017/05/acima-associacaocultural-italiana-de.html. Acesso em 18 junho 2018.

Portal da cidade de Maravilha-SC. Disponível em: http://www.maravilha.sc.gov.br/cms/pagina/ver/codMapaItem/3628. Acesso em 16 junho 2018.

RAJAGOPALAN, K. O conceito de Identidade em linguística: é chegada a hora de uma consideração radical? In.: SIGNORINI, I. (Org.). Lingua(gem) e identidade: elementos para um discussão no campo aplicado. São Paulo: Mercado das Letras, 1998, p. 21-45.

VEDOVELI, M. Storia dell'emigrazione italiana nel mondo. CAROCCI: Roma, 2011. 